\title{
Production of Soybean Oil Nanoemulsion (SONE) and Evaluation of Angiogenic and Embryotoxic Activity
}

\author{
Tamíris Augusto Marinho',2, Patrícia Silva Nunes 2 (D), Paulo Roberto de Melo-Reis ${ }^{3}$ (D), \\ Mônica Rodrigues Ferreira Machado4 $\mathbb{C}^{\circ}$, Nelson Jorge Silva Júnior ${ }^{1,3}$ (i)
}

\footnotetext{
${ }^{1}$ Programa de Pós-Graduação Doutorado em Biotenologia e Biodiversidade (PGBB), Universidade Federal de Goiás (UFG), Goiânia, Brasil

${ }^{2}$ Núcleo de Estudos e Pesquisas em Promoção da Saúde (NUPPS), Instituto Federal de Educação, Ciência e Tecnologia de Goiás (IFG), Goiânia, Brasil

${ }^{3}$ Programa de Pós-Graduação Mestrado em Genética, Goiânia, Brasil

${ }^{4}$ Departamento de Ciências Biológicas, Laboratório de Pesquisa e Reprodução de Zebrafish (LABFISH), Universidade Federal de Jataí (UFJ), Jataí, Brasil

Email: tamiris.marinho@ifg.ebu.br
}

How to cite this paper: Marinho, T.A., Nunes, P.S., de Melo-Reis, P.R., Machado, M.R.F. and Silva Jr., N.J. (2020) Production of Soybean Oil Nanoemulsion (SONE) and Evaluation of Angiogenic and Embryotoxic Activity. Journal of Biomaterials and Nanobiotechnology, 11, 161-178.

https://doi.org/10.4236/jbnb.2020.113010

Received: April 9, 2020

Accepted: May 30, 2020

Published: June 2, 2020

Copyright $\odot 2020$ by author(s) and Scientific Research Publishing Inc. This work is licensed under the Creative Commons Attribution International License (CC BY 4.0).

http://creativecommons.org/licenses/by/4.0/

\section{(c) (i) Open Access}

\begin{abstract}
The SONE oil/water was prepared using the pseudo-ternary phase diagram, using a low energy method with phase inversion by changing the composition. In order to optimize the preparation of SONE, three speeds were used in the agitator arm and two different rods. The particle size and polydispersity index were determined by Dynamic Light Scattering (DLS) and the stability test by the freeze-thaw cycle. Angiogenesis in chicken embryo egg chorioallantoic membrane and zebrafish (Danio rerio) embryotoxicity was performed. The lower stirring speed and propeller shaft induced smaller particle size $(550.2 \mathrm{~nm})$. Regarding angiogenesis, there was a statistically significant difference for all the evaluated parameters (length, caliber, junctions, and number of blood vessel complexes) and the result was higher in SONE when compared to the inhibition control (Dexamethasone), but lower than the induction control (Regederm ${ }^{\oplus}$ ) and there was no statistically significant difference between SONE and distilled water. It was observed that the exposure of the zebrafish embryos to SONE caused an increase in the mortality rate dependent on time and concentration. The $\mathrm{LC}_{50}$ for SONE decreased statistically with increasing exposure ( $\mathrm{p}$-value $=0.046$ ). Heart rate decreased significantly with increasing concentration at all exposure times (p-value $<0.05$ ), as a result of progressive embryo mortality. The hatching rate was late until the concentration of $0.0193 \mathrm{mg} / \mathrm{mL}$ and no hatching rate was verified from that concentration. Exposure of zebrafish embryos to different concentrations of
\end{abstract}


SONE induced malformations such as spinal changes, pericardial edema and yolk sac edema, but there was no significant difference in the malformation rate of embryos exposed to SONE when compared to the control group. The SONE produced remained stable in the freeze-thaw cycle, with changes only in $\mathrm{pH}$. Despite the low results for embryotoxicity, further studies are needed, aiming at the ideal formulation for angiogenesis purposes.

\section{Keywords}

Soybean Oil, Angiogenesis Inducing Agents, Toxicity, Biotechnology, Nanotechnology

\section{Introduction}

The production of soybean oil is a global highlight, and Brazil is the second largest producer and exporter, responsible for approximately $30 \%$ of the global production [1]. Soy oil is manufactured by mechanical pressing and solvent extraction of soya beans. Glycine $\max (\mathrm{L}$.) Merr. has an excellent fatty acid profile, including linoleic acid, oleic acid and linolenic acid [2]. Fatty acids are relevant in the healing of skin wounds by activating AKT, ERK, and TGF- $\beta /$ Smad3, signaling and promoting angiogenesis [3].

In particular, due to its abundance in the market and its low cost, soybean oil has been reported to be popularly used in skin wounds [4], recovery of the skin barrier, antibacterial effect, reduction of transdermal water loss associated with the presence of phytosterols, also proving effective in the treatment of UVB-induced skin erythema [5]. In addition, it was investigated in the literature and showed a decrease in fibrosis and prevention of peritoneal adhesions in the postoperative period [6].

The development of formulations including derivatives of plant origin, allows for the creation of new products with less risk of adverse reactions. It has been shown that in formulations, especially for topical application, the inclusion of fixed oils has a favorable cosmetic and pharmacological action on skin repair and protection. In this context, oils play the role of functional vehicles, excipients and constituents of the oil phase of emulsions [7].

In recent years, nanoemulsions (NEs) have been used as new administration systems seeking to improve the bioavailability of formulations. NEs offer advantages due to their ease and low cost of preparation, physical stability and nanometric diameter of particles that provides greater reactivity with biological cells. They present better sensorial aspect, penetration and absorption in the skin, greater control of release of products, apart from less amount of surfactants, reducing possible irritations [8] [9] [10].

The development of NEs designed for several applications requires in vivo toxicological studies to assess the potential effects on human safety. Zebrafish has been considered a "gold standard" for its high degree of genomic homology 
with humans, cost-benefit, well-characterized development stages, and optical transparency [11]. Previous studies using zebrafish have shown that this method allows for the evaluation of various toxic aspects of the tested substances, including decreased heart rate, yolk sac edema, pericardial edema, spinal cord alteration, inhibition of hatching rate, lethal concentration $\left(\mathrm{LC}_{50}\right)$, and mortality rate [12] [13].

Skin wounds entail financial costs for individuals, families, communities and public authorities; and it becomes relevant to identify new treatments from products made with biotechnological innovation. Thus, even with the increasing research of NEs, there are no reports in the literature on the NE production of soybean oil aiming at possible angiogenic effects and embryotoxicity. Therefore, seeking to innovate in the creation of a new product for use in health different from those already existing and available in the literature, the present study aimed to: 1) develop a soybean oil NE and perform preliminary stability tests and 2) assess, in vivo, angiogenic and embryotoxicity effects.

\section{Material and Methods}

\subsection{Development of Soybean Oil Nanoemulsion}

The soybean oil NE (SONE) oil/water (O/W) was prepared using the pseudo-ternary phase diagram, using a low energy method with phase inversion by changing the composition [14], with the following products: Liza commercial soybean oil (Cargill, Rio Verde, Goiás, Brazil) (Hydrophile-Lipophile Balance = 7.0), surfactants-Sorbitan Sesquioleate (Span 83) (Hydrophile-Lipophile Balance $=3.7$ ) (Lipo do Brasil, São Bernardo do Campo, São Paulo, Brazil) e Polysorbate 80 (Tween ${ }^{\circ}$ 80) (Hydrophile-Lipophile Balance $\left.=15.0\right)$ (Oxiteno, São Paulo, São Paulo, Brazil), Purified water by reverse osmosis (OS 1OLX, Gehaka, São Paulo, São Paulo, Brazil), Phenova microbiological preservative (Croda do Brasil, Campinas, São Paulo, Brazil). Initially, the aqueous phase and the oil phase were heated separately to $75^{\circ} \mathrm{C} \pm 2{ }^{\circ} \mathrm{C}$. Then, the oil phase was added slowly to the aqueous phase under constant stirring (IKA RW 20, Staufen, Baden-Württemberg, Germany) until the mixture reaches room temperature $\left(25^{\circ} \mathrm{C}\right.$ $\pm 2^{\circ} \mathrm{C}$ ). Finally, the microbiological preservative was added [15].

\subsection{Preliminary Stability Tests}

The SONE was evaluated macroscopically 24 hours after preparation, being subjected to centrifugation in triplicate, at the speed of $3000 \mathrm{rpm}$ for 30 minutes to identify possible instability [16]. Particle size and polydispersity index were determined by Dynamic Light Scattering Analyser (Dynamic Light Scattering-DLS) (Zetasizer Nano ZS90, Malvern, United Kingdom) [17].

Subsequently, in order to optimize SONE production, three different agitation speeds were tested on the agitator arm: $600 \mathrm{rpm}, 900 \mathrm{rpm}$ and $1200 \mathrm{rpm}$ (IKA RW 20, Staufen, Baden-Württemberg, Germany) and two rods: $\operatorname{cog}(\mathrm{H} 1)$ and helix (H2) (Figure 1) [18]. pH was measured by a phmeter (PG 1800 Gehaka, 


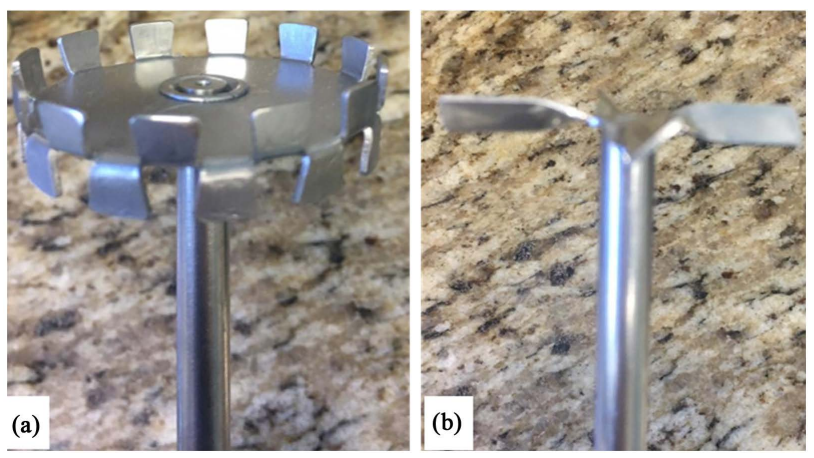

Figure 1. Rods used to optimize the preparation of nanoemulsions: (a) $\operatorname{cog}(\mathrm{H} 1)$ and (b) helix (H2).

São Paulo, São Paulo, Brazil). The index of refraction (IR) was obtained by a refractometer (Abbe, Baush and Lomb Optical Company, New York, United States of America). Electrical conductivity was assessed using the Digimed conductivity meter (DM32, Digimed, São Paulo, São Paulo, Brazil). Finally, the determination of absolute and relative density was performed using the pycnometer (SpLabor, Presidente Prudente, São Paulo, Brazil). All tests were performed in triplicate [19].

Still, the thermal stress was accomplished by heating in a thermostatic bath (NT 281 Nova Técnica Ltda, Santa Rosa, Piracicaba, São Paulo, Brazil) at a temperature of $45^{\circ} \mathrm{C} \pm 2^{\circ} \mathrm{C}$ to $80^{\circ} \mathrm{C} \pm 2^{\circ} \mathrm{C}$, gradually increasing the temperature every $4^{\circ} \mathrm{C} \pm 2^{\circ} \mathrm{C}$ and each value was maintained for 30 minutes, with macroscopic analysis to observe the phase separation at each temperature change. The SONE freeze-thaw cycle was submitted to a temperature of $45^{\circ} \mathrm{C} \pm 5^{\circ} \mathrm{C}$ for 24 hours and then to a temperature variation of $4^{\circ} \mathrm{C} \pm 2^{\circ} \mathrm{C}$ also for 24 hours, completing a cycle. Macroscopic evaluation and analysis of physical-chemical parameters were performed in the sixth and twelfth cycle [20].

\subsection{Assessment of Angiogenic Activity}

Chicken embryonated eggs (Gallus domesticus) were incubated in an automatic oven at $37^{\circ} \mathrm{C}$ and $60 \%-70 \%$ relative humidity for sixteen days. On the fifth day of incubation, a circular opening in the eggshell was performed in a laminar flow chamber using a micro-rectifier (Dremel MultiPro, Ouro Preto, Minas Gerais, Brazil). Soon after, a drop of $0.9 \% \mathrm{NaCl}$ was added over the already vascularized chorioallantoic membrane (CAM). The opening was sealed with adhesive tape and a new incubation was carried out.

At the end of the thirteenth day of incubation, filter paper discs were placed directly on the CAM soaked with the test substance: SONE produced, negative control: sterile distilled water (Samtec Biotecnologia, Ribeirão Preto, São Paulo, Brazil), induction control: Regederm (Pele Nova Biotecnologia, São Paulo, São Paulo, Brazil) and inhibition control: injectable dexamethasone $4 \mathrm{mg} / \mathrm{mL}$ (Aché Laboratórios Farmacêuticos S.A., Guarulhos, São Paulo, Brazil). The eggs were returned to the incubation until the sixteenth day [21]. 
On the sixteenth day of incubation the CAMs were removed, fixed with formaldehyde solution $3.7 \%$ for 5 minutes and cut with blunt curved scissors and kept in Petri dishes in the presence of $10 \%$ formaldehyde solution to obtain photo registration $(640 \times 480$ pixels; RGB 24 bits $)$ for analysis and quantification of a newly-formed vascular [22].

\subsection{Embryotoxicity Assessment}

Acute embryotoxicity tests on zebrafish embryos followed OECD 236 recommendations. Experimentation was performed with embryos from adult fish placed under ideal conditions, 60 males and 20 females in aquariums with water recirculation system $\left(28.5^{\circ} \mathrm{C} \pm 2^{\circ} \mathrm{C}, 80 \%\right.$ humidity) and the photoperiod was adjusted to a 14 hours light/10 hours dark cycle, fed four times a day with commercial floccular feed (FlakesFood) and Artemia salina. For experiments, embryos from reproduction were collected, transferred to Petri dishes containing E3 solution and classified aided by stereomicroscope (OLYMPUS CX 31, Shinjuku, Tokyo, Japan) as good, intermediate, bad and non-fertilized, using as standard: cell coloration, disposition and proliferation, in addition to egg fertilization and malformation [23].

After selection, the embryos classified exclusively as good were placed in polypropylene plates, white in color and transparent bottom with 96 wells. Twelve different serial dilutions of SONE were tested at the initial concentration of 124 $\mathrm{mg} / \mathrm{mL}$ and negative control (E3 solution) in 5 replicates. The solutions were changed daily and kept at room temperature. Embryonic developmental stages were evaluated for: decreased heart rate, yolk sac edema, pericardial edema, spinal cord alteration, hatching rate inhibition, lethal concentration $\left(\mathrm{LC}_{50}\right)$ and mortality rate through photos and/or videos were obtained in the periods of 0 , $48,72,96,120,144$ and 168 hours passed after fertilization (hpf) using the light microscope (LEICA DM750, Leica Microsystems, Rio de Janeiro, Rio de Janeiro, Brazil) coupled to the ICC50 HD digital camera and the LAS ${ }^{\circledR}$ EZ3.0.0 software [24].

\subsection{Statistical Analysis}

For analysis of the preliminary stability tests of SONE, the results were presented as mean $( \pm)$ standard deviation. The analysis of the variance values was analyzed by repeated (ANOVA) measurements followed by post hoc analysis using a $\mathrm{Tu}$ key test with a $\mathrm{p}<0.05$ significance, using GraphPad Prism, version 7.0 (Graph Pad, San Diego, California, United States of America).

The data on angiogenic activity and embryotoxicity were analyzed using SPSS version 24.0 (IBM SPSS Statistics for Windows, Version 24.0. Armonk, New York, United States of America) and GraphPadPrism version 7.0. Initially, the normality variables of the study were verified by the Shapiro-Wilk test [25]. The parameters measured in angiogenic activity were presented for each group as median and interquartile range (QII). To compare the values found, the Kruskal-Wallis nonparametric test for independent samples was performed, fol- 
lowed by post hoc analysis by Dunn's test for multiple comparison in case of statistical significance [26] [27]. The parameters evaluated for embryotoxicity were presented as mean and standard error of the mean (SEM). The comparison of the values found in relation to the control group was performed by the Mann-Whitney test for independent samples, $\mathrm{p}$-values $(\mathrm{p}<0.05)$ were considered statistically significant. To determine the $\mathrm{LC}_{50}$, the Probit method was used.

\subsection{Ethical Aspects}

This study was approved by the Research Ethics Committee of the Pontifícia Universidade Católica de Goiás, PUC-Goiás, Brazil (Consubstantiated Report No. 8235150816/2018).

\section{Results}

\subsection{Soybean Oil Nanoemulsion}

The pseudo-ternary phase diagram guided the preparation of SONE, numbered from one to seven, with each phase described in Table 1.

The seven SONEs produced, initially with an agitation speed of $600 \mathrm{rpm}$ and with a $\mathrm{H} 2$ helix, were submitted to preliminary stability assessment by macroscopic analysis and centrifugation. In the macroscopic evaluation after 24 hours (Figure 2), the color was milky for all formulations, there was no bluish reflex and those identified as number three, four and five maintained normal aspects (Table 2). The SONE identified as number five was the most stable after centrifugation, being the only one in which no phase separation was observed and it obtained the smallest particle size $(550.2 \mathrm{~nm})$.

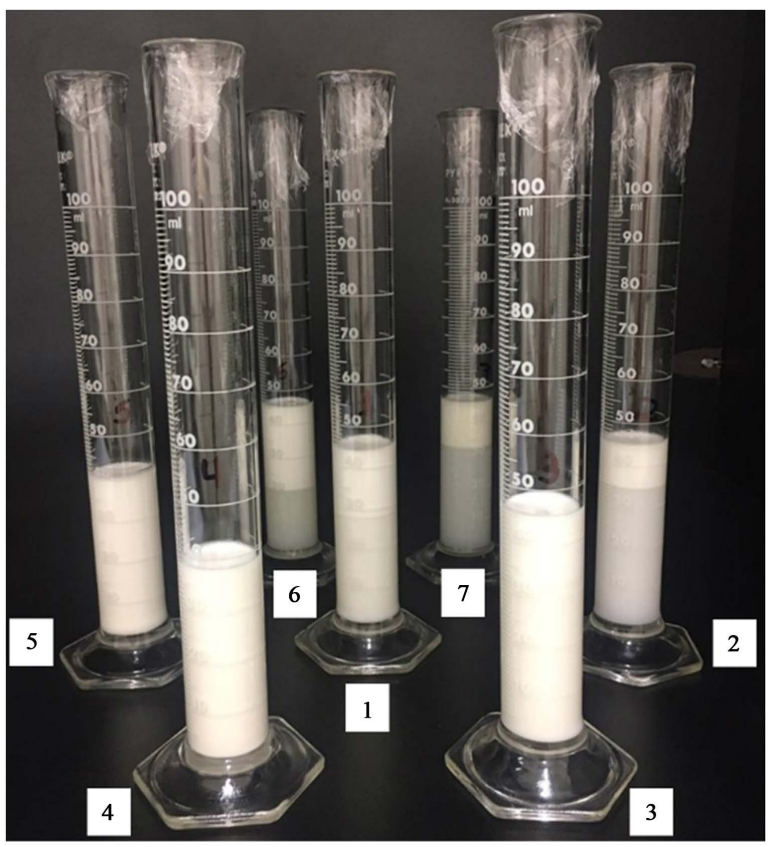

Figure 2. Macroscopic evaluation the SONEs initially produced after 24 hours at rest. 
Table 1. Formulations prepared using the phase diagram using soybean oil, surfactants and deionized water.

\begin{tabular}{cccc}
\hline \multirow{2}{*}{ Formulation } & \multicolumn{3}{c}{ Chemicals } \\
\cline { 2 - 4 } & Deionizedwater & Soybean oil & Surfactants (Span 83 + Tween 80) \\
\hline SONE 1 & $80 \mathrm{~mL}$ & $10 \mathrm{~mL}$ & $10 \mathrm{~mL}$ \\
SONE 2 & $85 \mathrm{~mL}$ & $10 \mathrm{~mL}$ & $5 \mathrm{~mL}$ \\
SONE 3 & $85 \mathrm{~mL}$ & $5 \mathrm{~mL}$ & $10 \mathrm{~mL}$ \\
SONE 4 & $80 \mathrm{~mL}$ & $5 \mathrm{~mL}$ & $15 \mathrm{~mL}$ \\
SONE 5 & $75 \mathrm{~mL}$ & $10 \mathrm{~mL}$ & $15 \mathrm{~mL}$ \\
SONE 6 & $75 \mathrm{~mL}$ & $15 \mathrm{~mL}$ & $10 \mathrm{~mL}$ \\
SONE 7 & $80 \mathrm{~mL}$ & $15 \mathrm{~mL}$ & $5 \mathrm{~mL}$ \\
\hline
\end{tabular}

Abbreviations: SONE $=$ Soybean oil nanoemulsion, $\mathrm{mL}=$ milliliters, Surfactants $($ Span $83+$ Tween 80$)$ used in equal proportions.

Table 2. Macroscopic characterization of the formulations prepared using soybean oil, surfactants and deionized water.

\begin{tabular}{cccc}
\hline Formulation & Transparent/Milky & Bluish Reflection & Aspect \\
\hline SONE 1 & $\mathrm{M}$ & No & $\mathrm{SM}$ \\
SONE 2 & $\mathrm{M}$ & No & $\mathrm{Mod}$ \\
SONE 3 & $\mathrm{M}$ & No & $\mathrm{N}$ \\
SONE 4 & $\mathrm{M}$ & No & $\mathrm{N}$ \\
SONE 5 & $\mathrm{M}$ & No & $\mathrm{N}$ \\
SONE 6 & $\mathrm{M}$ & No & Mod \\
SONE 7 & $\mathrm{M}$ & No & Mod \\
\hline
\end{tabular}

Abbreviations: SONE $=$ Soybean oil nanoemulsion, $\mathrm{T}=$ Transparent, $\mathrm{M}=$ Milky, No $=$ Not observed, $\mathrm{N}=$ Normal, SM = Slightly Modified, Mod = Modified.

In order to optimize the preparation process, SONE number five was tested with different speeds in the agitator arm of $600 \mathrm{rpm}, 900 \mathrm{rpm}$ and $1200 \mathrm{rpm}$. A difference in particle size was observed with the use of different speeds, with the lowest speed $(600 \mathrm{rpm})$ inducing the smallest size. A small difference in particle size was observed using different rods in the preparation and, in general, the $\mathrm{H} 2$ rods obtained better performance. The polydispersity index of all formulations was equal to or close to 1000 (Figure 3).

The formulation with the smallest particle size, shown in Figure 3(d) for SONE (550.2 nm), was chosen for follow-up and subjected to stability tests and to the freeze-thaw cycle (triplicate) (Table 3 ), which showed no statistically significant difference in any of the evaluated parameters. In the thermal stress evaluation, the appearance of creaming was observed at $75^{\circ} \mathrm{C}$ and after centrifugation, SONE did not present phase separation. 
Table 3. Characteristics of the SONEs prepared when subjected to the freeze-thaw cycle (in triplicate).

\begin{tabular}{|c|c|c|c|c|c|c|c|c|c|c|c|c|c|c|c|c|c|c|}
\hline Cycle & \multicolumn{6}{|c|}{ Before the cycle } & \multicolumn{6}{|c|}{ Sixth day of the cycle } & \multicolumn{6}{|c|}{ Twelfth day of the cycle } \\
\hline Sample & $\mathrm{pH}$ & IR & $\begin{array}{c}\text { Absol } \\
\text { Dens } \\
\left(\mathrm{g} / \mathrm{cm}^{3}\right)\end{array}$ & $\begin{array}{c}\text { Rel } \\
\text { Dens } \\
\left(\mathrm{g} / \mathrm{cm}^{3}\right)\end{array}$ & $\begin{array}{l}\text { Cond } \\
(\mu \mathrm{S} / \mathrm{cm} \\
\left.25^{\circ} \mathrm{C}\right)\end{array}$ & PS & $\mathrm{pH}$ & IR & $\begin{array}{c}\text { Absol } \\
\text { Dens } \\
\left(\mathrm{g} / \mathrm{cm}^{3}\right)\end{array}$ & $\begin{array}{c}\text { Rel } \\
\text { Dens } \\
\left(\mathrm{g} / \mathrm{cm}^{3}\right)\end{array}$ & $\begin{array}{c}\text { Cond } \\
(\mu \mathrm{S} / \mathrm{cm} \\
\left.25^{\circ} \mathrm{C}\right)\end{array}$ & PS & $\mathrm{pH}$ & IR & $\begin{array}{c}\text { Absol } \\
\text { Densid } \\
\left(\mathrm{g} / \mathrm{cm}^{3}\right)\end{array}$ & $\begin{array}{c}\text { Rel } \\
\text { Densid } \\
\left(\mathrm{g} / \mathrm{cm}^{3}\right)\end{array}$ & $\begin{array}{c}\text { Cond } \\
(\mu \mathrm{S} / \mathrm{cm} \\
\left.25^{\circ} \mathrm{C}\right)\end{array}$ & PS \\
\hline SONE 1 & 7.00 & & 0.9835 & 0.9853 & 202.1 & 550.2 & 7.62 & & 0.9858 & 0.9950 & 204.0 & 589.2 & 7.94 & & 0.9930 & 0.9948 & 204.1 & 578.2 \\
\hline SONE 2 & 7.22 & 1.3520 & 0.9829 & 0.9847 & 201.6 & 551.1 & 7.8 & 1.3520 & 0.9831 & 0.9912 & 201.8 & 555.2 & 8.04 & 1.3522 & 0.9926 & 0.9944 & 202.4 & 579.4 \\
\hline SONE 3 & 7.24 & & 0.9896 & 0.9913 & 200.9 & 554.3 & 7.71 & & 0.9911 & 0.9936 & 200.1 & 566.4 & 8.06 & & 0.9931 & 0.9949 & 202.0 & 599.7 \\
\hline Mean & 7.15 & & 0.98 & 0.99 & 201.5 & 551.5 & 7.71 & & 0.99 & 0.99 & 202.00 & 570.30 & 8.01 & & 0.99 & 0.99 & 202.83 & 586.80 \\
\hline SD & 0.13 & & 0.00 & 0.00 & 0.60 & 1.59 & 0.09 & & 0.00 & 0.00 & 1.95 & 17.32 & 0.06 & & 0.00 & 0.00 & 1.11 & 12.08 \\
\hline
\end{tabular}

Abbreviations: SONE $=$ Soy oil nanoemulsion, $\mathrm{Pt}=$ Parameter evaluated, $\mathrm{IR}=$ index of refraction, Absol Dens $=$ Absolute Density, Rel Density $=$ Relative Density, Cond = Electrical conductivity, PS = Particle Size, SD = Standard Deviation, ${ }^{*}$ Comparison of stability between times by Analysis of Variance (ANOVA): $\mathrm{pH}(\mathrm{p}$-value $=0.002)$, absolute density ( $\mathrm{p}$-value $=0.065)$, relative density ( $\mathrm{p}$-value $=0.063)$, conductivity $(\mathrm{p}$-value $=0.069)$ and PS $(\mathrm{p}$-value $=0.065)$.

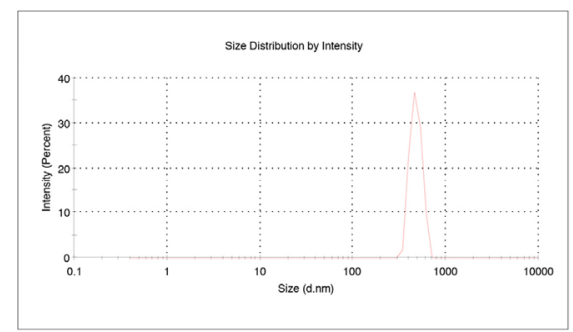

(a)

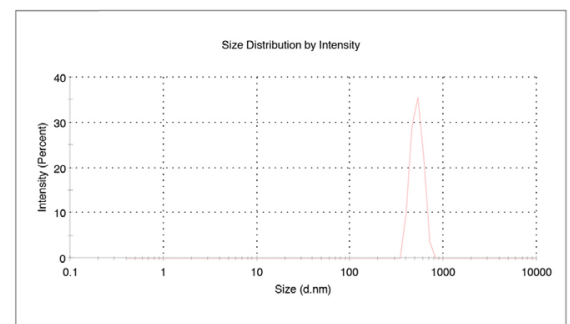

(c)

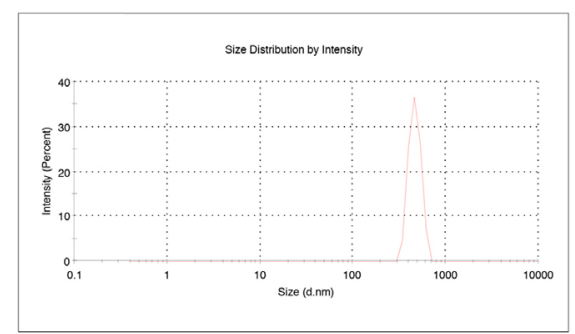

(e)

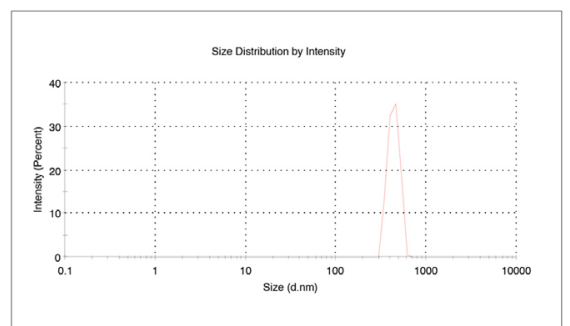

(b)

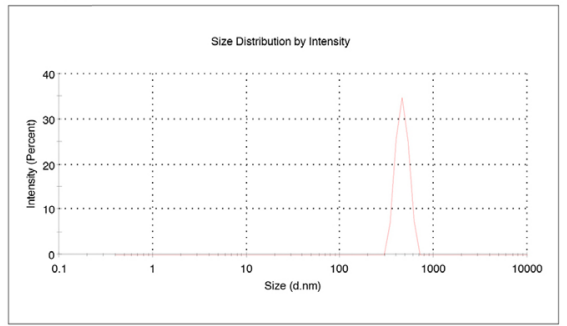

(d)

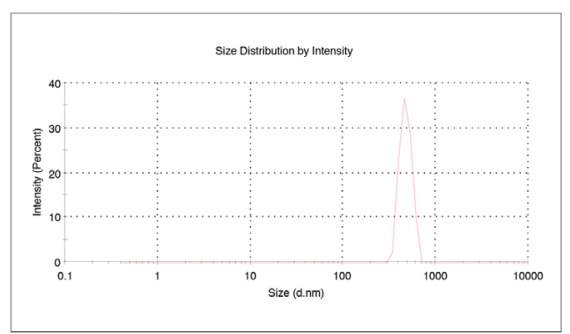

(f)

Figure 3. Particle size when changing the stem and speed simultaneously in preparing SONE number five. (a) H1/speed $600 \mathrm{rpm}=641.5 \mathrm{~nm}$ (nanometers); (b) H1/speed 900 $\mathrm{rpm}=658.1 \mathrm{~nm}$; (c) H1/speed $1200 \mathrm{rpm}=694.8 \mathrm{~nm}$; (d) H2/speed $600 \mathrm{rpm}=550.2 \mathrm{~nm}$; (e) $\mathrm{H} 2 /$ speed $900 \mathrm{rpm}=656.5 \mathrm{~nm}$; (f) H2/speed $1200 \mathrm{rpm}=657.9 \mathrm{~nm}$.

\subsection{Assessment of Angiogenic Activity}

The digital images obtained for the experiment (Figure 4) show, in the CAM treated with inhibition control (injectable dexamethasone), a reduction in the 

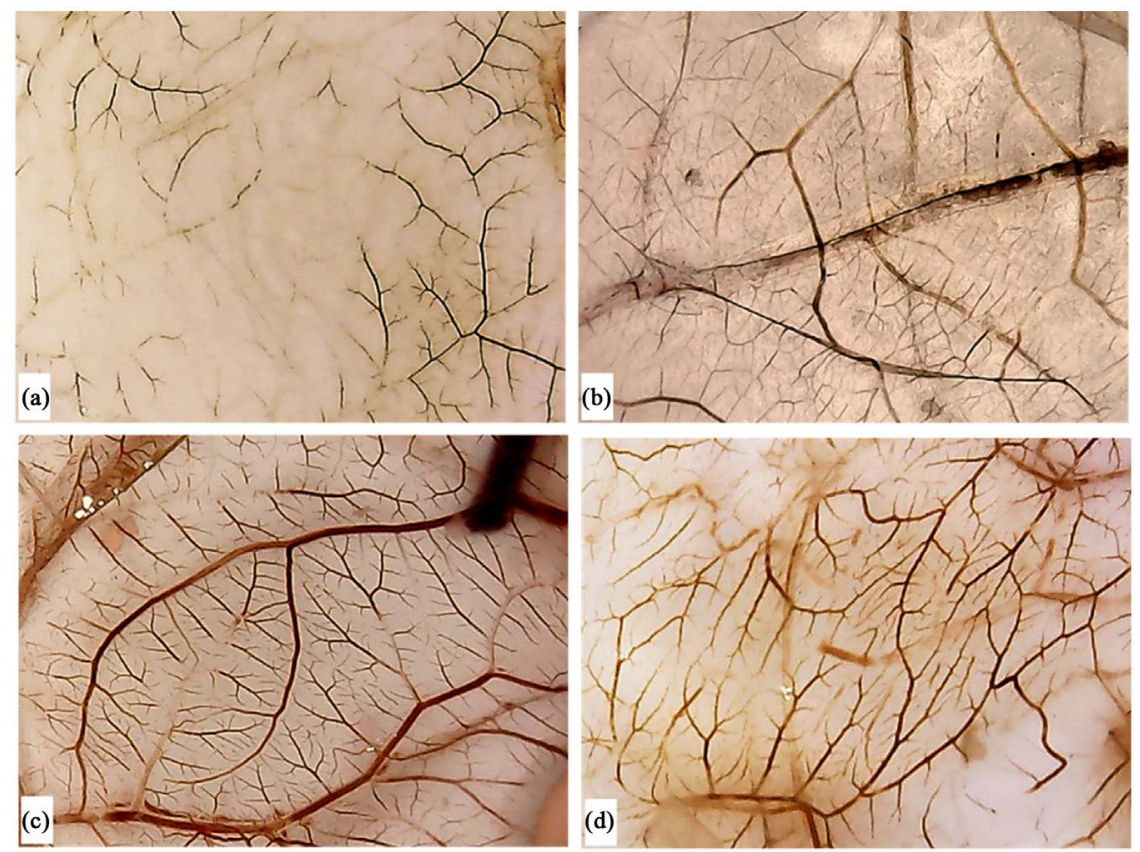

Figure 4. CAM treated with products: (a) Inhibition control: injectable dexamethasone; (b) Negative control: sterile distilled water; (c) Induction control: Regederm; and (d) SONE test substance.

quantity of vessels while, in the negative control (sterile distilled water), maintenance of the expected quantity of vessels, in the induction control (Regederm $^{\circ}$ ), an increase in the newly formed vascular network and, for the SONE test substance, a pattern similar to sterile distilled water is noted.

Table 4 and Figure 5 summarize the descriptive and comparative analysis between groups to assess the potential of the SONE test substance for angiogenesis. There was a statistically significant difference between groups for all the parameters evaluated ( $\mathrm{p}$-value $<0.001$ ). Length, caliber, junctions, and number of blood vessel complexes were higher in SONE when compared to the inhibition control (Dexamethasone), but lower than in the induction control (Regederm ${ }^{\circ}$ ), with a statistically significant difference. Still, there was no statistically significant difference between the SONE substance and distilled water for all parameters.

\subsection{Embryotoxicity Assessment}

Figure 6 summarizes the assessment of the mortality rate, $\mathrm{LC}_{50}$, heart rate and hatching rate of SONE. There were statistically higher mortality rates in zebrafish embryos exposed to SONE when compared to the control group from the concentration of $0.0193 \mathrm{mg} / \mathrm{mL}$ at $24 \mathrm{hpf}$ and $48 \mathrm{hpf}$ and from the concentration of $0.096 \mathrm{mg} / \mathrm{mL}$ at $72 \mathrm{hpf}$. From the concentration of $0.0775 \mathrm{mg} / \mathrm{mL}$, mortality rates of $100 \%$ have been verified in the vessels exposed to SONE in all periods of exposure. Thus, it was observed that exposure to SONE from zebrafish embryos caused an increase in the time-concentration dependent mortality rate (Figure $6(a))$. 


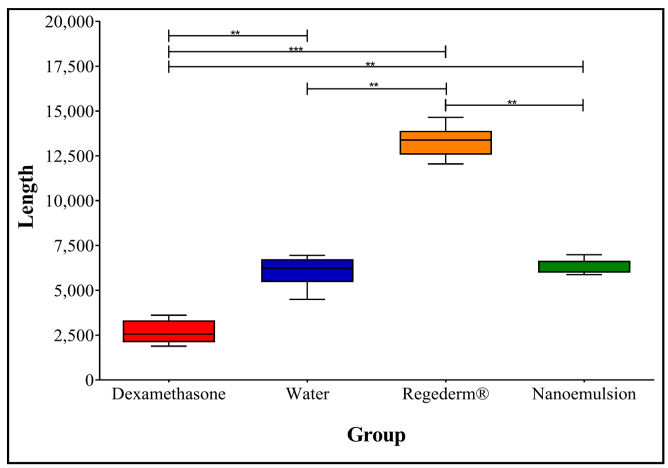

(a)

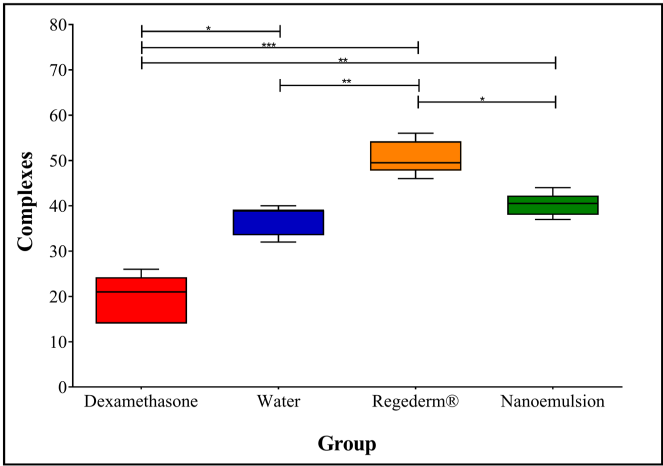

(c)

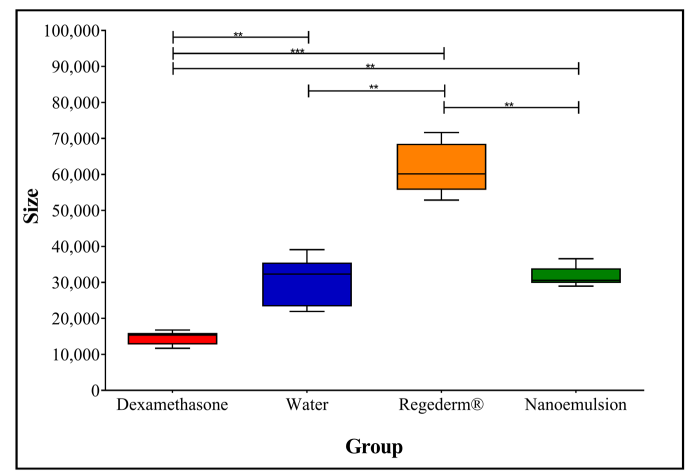

(b)

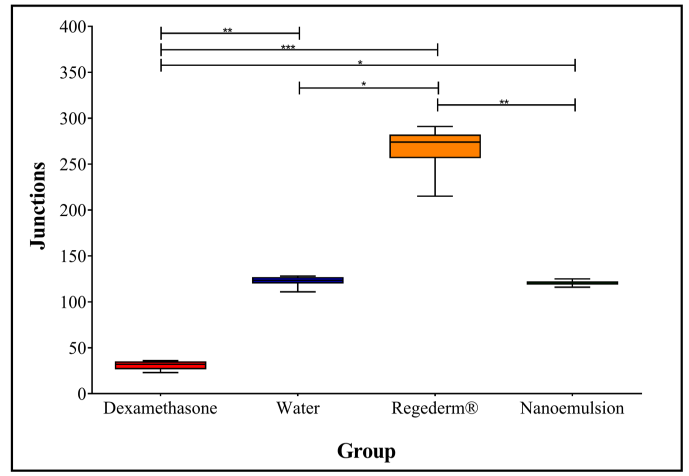

(d)

Figure 5. CAM treated with products: (a) inhibition control: injectable dexamethasone; (b) negative control: sterile distilled water; (c) induction control: Regederm; and (d) SONE test substance.

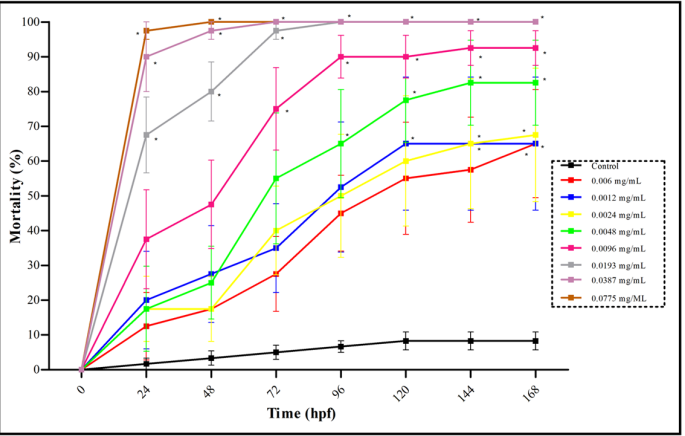

(a)

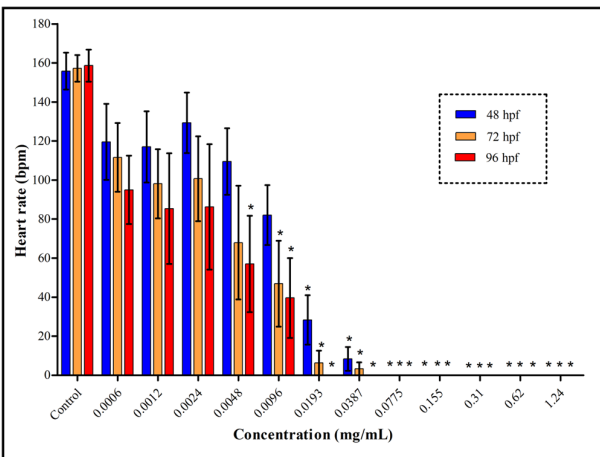

(c)

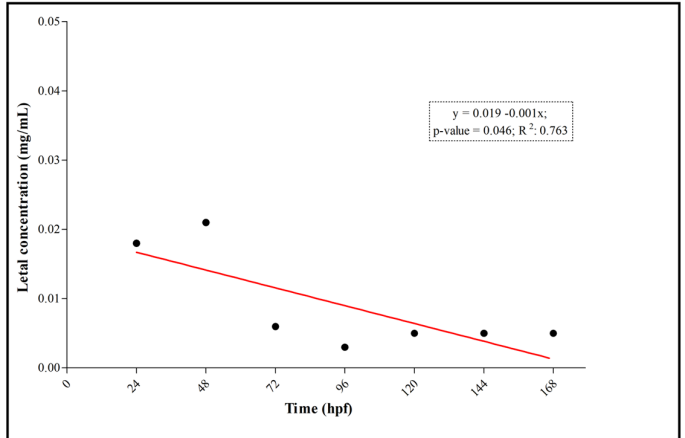

(b)

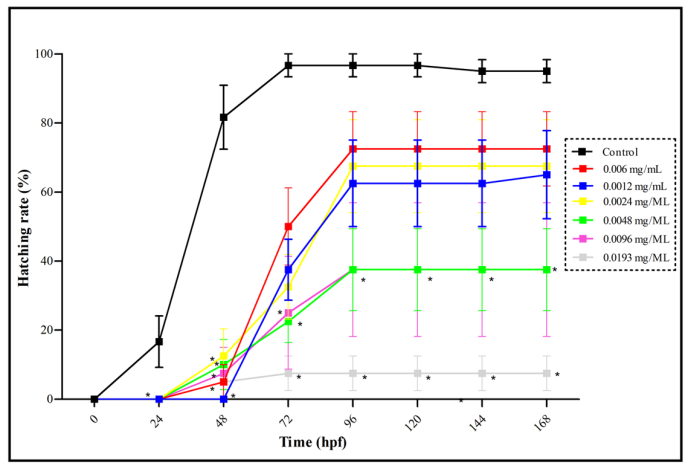

(d)

Figure 6. (a) Mortality rate; (b) $\mathrm{LC}_{50}$; (c) Heart rate and (d) Hatching rate in zebrafish embryos exposed to SONE. 
Table 4. Macroscopic characterization of the formulations prepared using soybean oil, surfactants and deionized water.

\begin{tabular}{ccccccc}
\hline Parameters $^{*}$ & Dexamethasone & Water & Regederm & SONE & H $^{* *}($ d.f. $)$ & p-value \\
\hline \multirow{2}{*}{ Length } & 2553.95 & 6225.75 & $13,349.00$ & 6036.65 & $32.93(3)$ & $<0.001$ \\
& $(1223.55)$ & $(1277.00)$ & $(1325.85)$ & $(665.00)$ & & \\
Caliber & $15,382.50$ & $32,329.50$ & $60,176.50$ & $30,568.00$ & $32.97(3)$ & $<0.001$ \\
& $(3189.75)$ & $(12,193.75)$ & $(12,813.25)$ & $(4069.25)$ & & \\
Junctions & 32 & 123.50 & 274.0 & 119.50 & $33.77(3)$ & $<0.001$ \\
& $(8.75)$ & $(7.0)$ & $(25.75)$ & $(3.50)$ & & \\
Complexes & 21.0 & 39.0 & 49.50 & 40.50 & $34.22(3)$ & $<0.001$ \\
& $(10.25)$ & $(5.50)$ & $(6.50)$ & $(4.25)$ & & \\
\hline
\end{tabular}

Abbreviations: d.f. $=$ degrees of freedom, ${ }^{\star}$ Data presented as median $(\mathrm{IQR}),{ }^{* *}$ Kruskal-Wallis test for independent samples.

The SONE $\mathrm{LC}_{50}$ varied from $0.0180 \mathrm{mg} / \mathrm{mL}$ to $0.0050 \mathrm{mg} / \mathrm{mL}$ between $24 \mathrm{hpf}$ and $168 \mathrm{hpf}(\Delta \%=-72.2)$, with $\mathrm{LC}_{50}$ decreasing statistically with increasing exposure $(\mathrm{p}$-value $=0.046)($ Figure $6(\mathrm{~b}))$.

Heart rate decreased significantly with increasing concentration at all exposure times (p-value $<0.05$ ), a result of progressive embryo mortality. The heartbeat of the larvae of the zebrafish embryos exposed to differences in concentrations and periods showed no significant difference with the control group up to the concentration of $0.0048 \mathrm{mg} / \mathrm{mL}$ at $96 \mathrm{hpf}$. From that concentration and persisting until the final concentration $(1.24 \mathrm{mg} / \mathrm{mL})$, it was found that the heart rate of the control group was statistically higher than that of SONE at $96 \mathrm{hpf}$ (p-value $<0.05$ ). At $72 \mathrm{hpf}$ and $48 \mathrm{hpf}$, significant differences in heart rate were verified from the concentrations of $0.0096 \mathrm{mg} / \mathrm{mL}$ and $0.0193 \mathrm{mg} / \mathrm{mL}$, respectively (Figure 6(c)).

The analysis of the hatching rate of zebrafish embryos showed that embryos exposed to SONE showed late hatchability until the concentration of 0.0193 $\mathrm{mg} / \mathrm{mL}$, while no hatching rate was verified from that concentration, resulting from the mortality of the embryos. At $24 \mathrm{hpf}$ and $48 \mathrm{hpf}$, no or low hatch rate was observed in all SONE concentrations, which differed statistically from the hatch rate observed in the control group (p-value < 0.05) (Figure 6(d)).

Exposure of zebrafish embryos to different concentrations of SONE induced malformations such as spinal cord alteration, edema of the pericardium and edema of the yolk sac at a rate of less than $10 \%$ in all concentrations. However, there was no significant difference in the rate of malformations of embryos exposed to SONE when compared to the control group: rate of pericardial edema, yolk sac edema, and spinal cord alteration.

\section{Discussion}

Regarding SONE stability, those changes in $\mathrm{pH}$ indicate the occurrence of chemical reactions that can compromise the quality of the final product. Values close to the $\mathrm{pH}$ of the major component are recommended, the SONE $\mathrm{pH}$ re- 
mained close to the neutral value, similar to water (75\% of SONE), which allows for greater stability of the oil particles. However, a statistically significant increase in $\mathrm{pH}$ with storage time can be justified by better solubilization of the oil phase with the surfactant. Still, it is noteworthy that the skin and mucous membranes have a slightly acidic $\mathrm{pH}$, being able to secrete buffering substances tolerating products with $\mathrm{pH}$ values between 3 and 9 , a result that favors the topical use of SONE [28].

It is described in the literature that changes in the $\mathrm{pH}$ value may be due to oxidative processes of the components of the formulation, mainly of the oily phase, such as vegetable oils that are susceptible to self-oxidation when exposed to atmospheric oxygen or to high temperatures, forming hydroperoxides or triglyceride hydrolysis leading to the formation of free fatty acids which reduces the $\mathrm{pH}$ of the formulation and compromises the quality of the final product, a result not observed in the present study [28].

The relative density for SONE showed values close to the density of water and this physical-chemical parameter did not change during the freeze-thaw cycle, suggesting no incorporation of air or the loss of volatile ingredients in the products [19].

The SONE index of refaction showed a small decrease in relation to the value of pure soybean oil, which ranges from 1.4700 to 1.4760 . In general, the index of refraction is directly proportional to the amount of oil in the emulsion, so as the amount of oil in the formulation is small (10\%), the refractive index has decreased. This result is consistent with density since less dense systems have a lower index of refraction [2].

Electrical conductivity did not show statistically significant changes in the freeze-thaw cycle. The stability of NEs is directly related to electrical conductivity and NEs of the O/W type are better conductors when compared to the water/oil (W/O) type [29]. The variations in electrical conductivity are due to the occurrence of chemical instability processes, which can cause the release of ions in the aqueous medium, increasing the conduction of electrical current [30]. Correlating an electrical conductivity analysis with a $\mathrm{pH}$ assessment, it is proposed that there was no hydrolysis process, because there was no decrease in $\mathrm{pH}$ [28].

In fact, a change was observed in SONE in a single parameter in the freeze-thaw $\mathrm{pH}$ cycle. A published research that investigated the influence of the addition of plant products (ethoxylated and acetylated lanolin) in NEs observed changes in two parameters: particle size and electrical conductivity, but there was no change in $\mathrm{pH}$ values [31].

The small size of the particles, in addition to contributing to stability, facilitates penetration into the skin layers, corroborating the good topical action of NEs. For formulations produced with soybean oil, the one with the smallest particle size was $550.2 \mathrm{~nm}$, a size compatible with our goal of producing an NE that would enable better penetration of soybean oil in relation to the original product [32]. 
In the current study, it was observed that a lower agitation speed used in the preparation $(600 \mathrm{rpm})$ and the propeller shaft induced a smaller particle size. Another published work evaluated the addition of lavender essential oil in passion fruit oil NEs, identifying the agitation speed as an important parameter in obtaining the NEs by the low-energy method by phase inversion, showing that the lowest agitation speed used $(600 \mathrm{rpm})$ was more effective in inducing nanometric particle size, these results being similar to those observed in SONE. In addition, another similarity was instability with increased temperature due to thermal stress [18]. Still, for the copaíba oil NE, the preparation was investigated by two methods: high homogenization pressure (high energy method) and spontaneous emulsification (low energy method) and the observed particle size was the same for both methods, showing that the increase in the energy used is not the determining factor in the induction of nanometer sized particles [33].

In addition to the size of the particles, it is relevant to determine the polydispersity index that shows the quality of the dispersion of the nanometric particles and the probability of instability over time. The polydispersity index of SONE remained the same during the change in the agitation speed and rods used, being equal to or close to 1000, showing polydispersed nanometric systems and a consequent greater risk of instability over time. It is described in the literature that NEs obtained by low energy methods tend to have a higher polydispersity index [33] [34].

Clove oil irritating to the skin under topical application had its action against Candida spp. improved in use as NE, with reduced toxicity [35] and the eucalyptus oil NE obtained a good rate of wound contraction [36]. In another study for NEs also based on clove oil and eucalyptus oil, a healing effect was evidenced in vivo [37] [38]. For SONE, unfortunately we observed a pattern similar to sterile distilled water and inferior to Regederm in the assessment of angiogenic activity. Meantime, this data is consistent with the proportion of the formulation in $75 \%$ water. We emphasize the importance of complementary studies capable of elucidating the complexity of the formulation techniques and underlying production principles, highlighting the influence of the mixture of the components used in the formulation: water, oil, surfactants, and preservatives [39].

Regarding the possible effects of acute toxicity by the zebrafish embryotoxicity test (ZET), studies involving nanoproducts, especially nanoemulsions, are scarce, being unprecedented for SONE. A published research that evaluated metallic nanoparticles (NPs) observed greater acute toxicity for silver (Ag) NPs with values as low as $\mathrm{LC}_{50} 0.529 \mathrm{mg} \mathrm{Ag} \mathrm{L^{-1 }}$ for $20 \mathrm{~nm} \mathrm{Ag} \mathrm{NPs.} \mathrm{In} \mathrm{general,} \mathrm{they}$ concluded that the result of the ZET can be influenced by the chemical composition and solubility of the NPs [40]. In the present study, the SONE LC $_{50}$ showed values ranging from $0.0180 \mathrm{mg} / \mathrm{mL}$ to $0.0050 \mathrm{mg} / \mathrm{mL}$ between $24 \mathrm{hpf}$ and 168 hpf $(\Delta \%=-72.2)$ with a statistically significant decrease with increasing exposure time $(\mathrm{p}$-value $=0.046)$.

In relation to the cardiocirculatory system, in zebrafish embryos, the system is closed and the heart is the first organ to be formed during embryonic develop- 
ment, as in other vertebrates, and the physiology is highly representative for humans [41]. Zebrafish embryos exposed to cobalt ferrite $\left(\mathrm{CoFe}_{2} \mathrm{O}_{4}\right) \mathrm{NPs}$ and acute toxic outcomes resulted in dose-time dependent toxicity, presence of severe cardiac edema, and negative regulation of metabolism [42]. For SONE, heart rate decreased significantly with increasing concentration at all exposure times ( $\mathrm{p}$-value $<0.05$ ), being lower than the control and also dose-dependent.

It is noteworthy, on cardiac alterations, that the Azoxystrobin fungicidewas nanoencapsulated and tested for embryotoxicity in zebrafish, observing an increase in the yolk sac, this reduced consumption of yolk being correlated with reduced oxygen consumption and a consequent reduction in heart rate [43]. Thus, the reduction in heart rate is directly related to the decrease in oxygen consumption and consequent mortality. For the NOSE at the highest concentrations, there was a lower or absent heart rate and, therefore, higher mortality.

In relation to the hatching rate, in titanium dioxide $\left(\mathrm{TiO}_{2}\right) \mathrm{NPs}$, as morphometric characteristics related to hatching rate, delays were observed in hatching time which can affect larval development, accelerating mortality [44]. In copper nanoparticles, a delay was noticed in the hatching of embryos and caused the killing of the gastrula-stage zebrafish embryos high concentrations $(>0.1 \mathrm{mg} / \mathrm{L})$ [45]. For the present study, our results were similar: the embryos that were exposed present SONE late hatchability up until a concentration of $0.0193 \mathrm{mg} / \mathrm{mL}$, thereafter there was no hatching and mortality was $100 \%$ in zebrafish embryos.

In another two studies with polystyrene using the zebrafish embryo as an animal model, synergistically dose-dependent effects on mortality, rate of closure and malformations [46], and reduced heart rate for polystyrene NPs were observed in polystyrene nanoplastics [47]. These data are similar to those observed for SONE with increased concentration: an increase in mortality, reduced heart rate and hatching rate were noted. However, for SONE, the malformations observed were not statistically significant.

\section{Conclusion}

In conclusion, the relevance was evidenced of technological innovation methods with the use of biotechnology for the production of new drugs, such as NEs, capable of generating new products for use in health using biomaterials. The SONE was produced in the search to optimize the use of soybean oil, with stability maintained during the freeze-thaw cycle, with changes only in $\mathrm{pH}$. In addition, in this unprecedented study, despite the low results for embryotoxicity, favorable data for health use, further studies on the subject are needed in order to understand the fundamentals for the ideal formulation, and its relationship with the pharmacological profile aiming at angiogenesis and stability.

\section{Conflicts of Interest}

The authors declare no conflicts of interest regarding the publication of this paper. 


\section{References}

[1] The American Soybean Association. https://soygrowers.com

[2] Amaral, L., Jaigobind, S.J. and Jaigobind, A.G.A. (2006) Technical Dossier Submitted to the Brazilian Technical Response Service (SBRT) Soy Oil. Paraná Institute of Technology. http://www.sbrt.ibict.br

[3] Zong, J., Jiang, J., Shi, P., Liu, J., Wang, W., Li, B., Zhao, T., Pan, T., Zhang, Z., Bi, L., Diao, Y. and Wang, S. (2020) Fatty Acid Extracts Facilitate Cutaneous Wound Healing through Activating AKT, ERK, and TGF- $\beta /$ Smad3 Signaling and Promoting Angiogenesis. American Journal of Translational Research, 12, 478-492.

[4] Pazyar, N., Yaghoobi, R., Rafiee, E., Mehrabian, A. and Feily, A. (2014) Skin Wound Healing and Phytomedicine: A Review. Skin Pharmacology and Physiology, 27, 303-310. https://doi.org/10.1159/000357477

[5] Lin, T.K., Zhong, L. and Santiago, J.L. (2017) Anti-Inflammatory and Skin Barrier Repair Effects of Topical Application of Some Plant Oils. International Journal of Molecular Sciences, 19, 1-22. https://doi.org/10.3390/ijms19010070

[6] Aysan, E., Bektas, H., Kaygusuz, A. and Huq, G.E. (2009) A New Approach for Decreasing Postoperative Peritoneal Adhesions: Preventing Peritoneal Trauma with Soybean Oil. Journal of Investigative Surgery, 22, 275-280. https://doi.org/10.1080/08941930903040148

[7] Manhezi, A.C., Bachion, M.M. and Pereira, A.L. (2008) Utilização de ácidos graxos essenciais no tratamento de feridas. Revista Brasileira de Enfermagem, 61, 620-628. https://doi.org/10.1590/S0034-71672008000500015

[8] Han, K.B., Takagi, C., Wu, C.J, Mizukami, H. and Ostafin, A. (2016) Synthesis of Calcium Phosphate Controllable Coating Thickness on Oil-in-Water Nanoemulsion with Performance of Oxygen Release as Oxygen Carrier. Journal of Biomaterials and Nanobiotechnology, 7, 55-63. https://doi.org/10.4236/jbnb.2016.72007

[9] Patnaik, S., Aditha, S.K., Rattan, T. and Kamisetti, V. (2015) Aceclofenac-Soluplus Nanocomposites for Increased Bioavailability. Soft Nanoscience Letters, 5, 13-20. https://doi.org/10.4236/snl.2015.52003

[10] Lovelyn, C. and Attama, A.A. (2011) Current State of Nanoemulsions in Drug Delivery. Journal of Biomaterials and Nanobiotechnology, 2, 626-639. https://doi.org/10.4236/jbnb.2011.225075

[11] Dumitrescu, E., Wallace, K. and Andreescu, S. (2019) Nanotoxicity Assessment Using Embryonic Zebrafish. Methods in Molecular Biology, 1894, 331-343. https://doi.org/10.1007/978-1-4939-8916-4_20

[12] Qian, L., Cui, F., Yang, Y., Liu, Y., Qi, S. and Wang, C. (2018) Mechanisms of Developmental Toxicity in Zebrafish Embryos (Danio rerio) Induced by Boscalid. Science of the Total Environment, 634, 478-487. https://doi.org/10.1016/j.scitotenv.2018.04.012

[13] Thiagarajan, S.K., Rama Krishnan, K., Ei, T., Husna Shafie, N., Arapoc, D.J. and Bahari, H. (2019) Evaluation of the Effect of Aqueous Momordica charantia Linn. Extract on Zebrafish Embryo Model through Acute Toxicity Assay Assessment. Evidence-Based Complementary and Alternative Medicine, 2019, Article ID: 9152757. https://doi.org/10.1155/2019/9152757

[14] Solans, C. and Solé, I. (2012) Nano-Emulsions: Formation by Low-Energy Methods. Current Opinion in Colloid \& Interface Science, 17, 246-254. https://doi.org/10.1016/j.cocis.2012.07.003

[15] Rocha-filho, P.A., Maruno, M., Oliveira, B., Bernard, D.S., Gumiero, V.C. and Pe- 
reira, T.A. (2014) Nanoemulsions as a Vehicle for Drugs and Cosmetics. NanoScience and Technology, 1, 5.

[16] Idson, B. (1993) Stability Testing of Emulsions. Drug and Cosmetic Industry, 142, 27-30.

[17] Tomaszewska, E., Soliwoda, K., Kadziola, K., Tkacz-Szczesna, B., Celichowski, G., Cichomski, M., Szmaja, W. and Grobelny, J. (2013) Detection Limits of DLS and UV-vis Spectroscopy in Characterization of Polydisperse Nanoparticles Colloids. Journal of Nanomaterials, 2013, Article ID: 313081. https://doi.org/10.1155/2013/313081

[18] Rocha-Filho, P.A., Camargo, M.F.P., Ferrari, M. and Maruno, M. (2014) Influence of Lavander Essential Oil Addition on Passion Fruit Oil Nanoemulsions: Stability and in Vivo Study. Journal of Nanomedicine \& Nanotechnology, 5, 198.

[19] National Health Surveillance Agency (2010) Brazilian Pharmacopoeia. http://portal.anvisa.gov.br/documents/33832/260079/5\%C2\%AA+edi\%C3\%A7\%C3 \%A3o+-+Volume+1/4c530f86-fe83-4c4a-b907-6a96b5c2d2fc

[20] National Health Surveillance Agency (2004) Stability Guide for Cosmetic Products. http://portal.anvisa.gov.br/documents/106351/107910/Guia+de+Estabilidade+de+P rodutos+Cosm\%C3\%A9ticos/49cdf34c-b697-4af3-8647-dcb600f753e2

[21] Almeida, L.M., Bailão, E.F.L.C., Pereira, I.R., Ferreira, F.A., D’Abadia, P.L., Borges, F.S.M., Lino-Júnior, R.S., de Melo-Reis, P.R. and Gonçalves, P.J. (2019) Antiangiogenic Potential of Jatropha curcas Latex in the Chick Chorioallantoic Membrane Model. Scientia Medica, 29, e32157.

https://doi.org/10.15448/1980-6108.2019.1.32157

[22] Araújo, L.A., Assunção, L.A., Silva-Júnior, N.J., Lemes, S.R. and Melo-Reis, P.R. (2015) Angiogenic Activity of Sucupira (Pterodon emarginatus) Oil. Scientia Medica, 25, 1-7. https://doi.org/10.15448/1980-6108.2015.2.20351

[23] Organization for Economic Cooperation and Development (OECD) (2013) Test No. 236: Fish Embryo Acute Toxicity (FET) Test. OECD Guidelines for the Testing of Chemicals, Section 2. OECD Publishing, Paris.

[24] Kimmel, C.B., Ballard, W.W., Kimmel, S.R., Ullmann, B. and Schilling, T.F. (1995) Stages of Embryonic Development of the Zebrafish. Developmental Dynamics, 203, 255-310. https://doi.org/10.1002/aja.1002030302

[25] Razali, N.M. and Wah, Y.B. (2011) Power Comparisons of Shapiro-Wilk, Kolmogorov-Smirnov, Lilliefors and Anderson-Darling Tests. J Stat Model Analytics, 2, 21-33.

[26] Kruskal, W.H. and Wallis, A. (1952) Use of Ranks in One-Criterion Variance Analysis. Journal of the American Statistical Association, 47, 583-621. https://doi.org/10.1080/01621459.1952.10483441

[27] Dunn, O.J. (1964) Multiple Comparisons Using Rank Sums. Technometrics, 6, 241-252. https://doi.org/10.1080/00401706.1964.10490181

[28] Masmoudi, H., Le dréau, Y., Piccerelle, P. and Kister, J. (2005) The Evaluation of Cosmetic and Pharmaceutical Emulsions Aging Process Using Classical Techniques and a New Method: FTIR. International Journal of Pharmaceutics, 289, 117-131. https://doi.org/10.1016/j.ijpharm.2004.10.020

[29] Togniolo, V., Azzini, R.G. and Rocha-Filho, P.A. (1999) Oil-Water-Oil (O-W-O) Multiple Emulsions: Multiplicity Control by Fluorescent Probe. Bolletino Chimico Farmaceutico, 138, 156-159.

[30] Bernardi, D.S., Pereira, T.A., Maciel, N.R., Bortoloto, J., Viera, G.S., Oliveira, G.C. 
and Rocha-Filho, P.A. (2011) Formation and Stability of Oil-in-Water Nanoemulsions Containing Rice Bran Oil: In Vitro and in Vivo Assessments. Journal of Nanobiotechnology, 28, 44. https://doi.org/10.1186/1477-3155-9-44

[31] Pereira, T., Guerreiro, C., Maruno, M., Ferrari, M. and Rocha-filho, P.A. (2016) Exotic Vegetable Oils for Cosmetic O/W Nanoemulsions: In Vivo Evaluation. Molecules, 21, 1-16. https://doi.org/10.3390/molecules21030248

[32] Tadros, T., Izquierdo, P., Esquena, J. and Solans, C. (2004) Formation and Stability of Nanoemulsions. Advances in Colloid and Interface Science, 108, 303-318. https://doi.org/10.1016/j.cis.2003.10.023

[33] Dias, D.O., Colombo, M., Kelmann, R.G., Kaiser, S., Lucca, L.G., Teixeira, H.F., Limbergera, R.P., Veiga Jr., V.F. and Koestera, L.S. (2014) Optimization of Copaiba Oil-Based Nanoemulsions Obtained by Different Preparation Methods. Industrial Crops and Products, 59, 154-162. https://doi.org/10.1016/j.indcrop.2014.05.007

[34] Leong, W.F., Lai, O.M., Long, K., Man, Y.B.C., Misran, M. and Tan, C.P. (2011) Preparation and Characterisation of Water-Soluble Phytosterol Nanodispersions. Food Chemistry, 129, 77-83. https://doi.org/10.1016/j.foodchem.2011.04.027

[35] Betzler, O.S.L., Matos, A.P.D.S., Cardoso, V.D.S., Villanova, J.C.O., Guimarães, B.D.C.L.R., Dos Santos, E.P., Beatriz Vermelho, A., Santos-Oliveira, R. and Ricci Junior, E. (2019) Clove Oil Nanoemulsion Showed Potent Inhibitory Effect against Candida spp. Nanotecnologia, 30, Article ID: 425101. https://doi.org/10.1088/1361-6528/ab30c1

[36] Sugumar, S., Ghosh, V., Nirmala, M.J., Mukherjee, A. and Chandrasekaran, N. (2014) Ultrasonic Emulsification of Eucalyptus Oil Nanoemulsion: Antibacterial Activity against Staphylococcus aureus and Wound Healing Activity in Wistar Rats. Ultrasonics Sonochemistry, 21, 1044-1049. https://doi.org/10.1016/j.ultsonch.2013.10.021

[37] Alam, P., Ansari, M.J., Anwer, M.K., Raish, M., Kamal, Y.K.T. and Shakeel, F. (2017) Wound Healing Effects of Nanoemulsion Containing Clove Essential Oil. Artificial Cells, Nanomedicine, and Biotechnology, 45, 591-597. https://doi.org/10.3109/21691401.2016.1163716

[38] Alam, P., Shakeel, F., Anwer, M.K., Foudah, A.I. and Alqarni, M.H. (2018) Wound Healing Study of Eucalyptus Essential Oil Containing Nanoemulsion in Rat Model. Journal of Oleo Science, 67, 957-968. https://doi.org/10.5650/jos.ess18005

[39] Tayeb, H.H. and Sainsbury, F. (2018) Nanoemulsions in Drug Delivery: Formulation to Medical Application. Nanomedicine (Lond), 13, 2507-2525. https://doi.org/10.2217/nnm-2018-0088

[40] Lacave, J.M., Retuerto, A., Vicario-Parés, U., Gilliland, D., Oron, M., Cajaraville, M.P. and Orbea, A. (2016) Effects of Metal-Bearing Nanoparticles (Ag, Au, CdS, $\mathrm{ZnO}, \mathrm{SiO}_{2}$ ) on Developing Zebrafish Embryos. Nanotechnology, 27, Article ID: 325102. https://doi.org/10.1088/0957-4484/27/32/325102

[41] Dahme, T., Katus, H.A. and Rottbauer, W. (2009) Fishing for the Genetic Basis of Cardiovascular Disease. Disease Models \& Mechanisms, 2, 18-22. https://doi.org/10.1242/dmm.000687

[42] Ahmad, F., Liu, X., Zhou, Y. and Yao, H. (2015) An in Vivo Evaluation of Acute Toxicity of Cobalt Ferrite $\left(\mathrm{CoFe}_{2} \mathrm{O}_{4}\right)$ Nanoparticles in Larval-Embryo Zebrafish (Danio rerio). Aquatic Toxicology, 166, 21-28. https://doi.org/10.1016/j.aquatox.2015.07.003

[43] Zhang, Y., Sheedy, C., Nilsson, D. and Goss, G.G. (2020) Evaluation of Interactive Effects of UV Light and Nano Encapsulation on the Toxicity of Azoxystrobin on 
Zebrafish. Nanotoxicology, 14, 232-249.

https://doi.org/10.1080/17435390.2019.1690064

[44] Samaee, S.M., Manteghi, N., Yokel, R.A. and Mohajeri-Tehrani, M.R. (2018) Morphometric Characteristics and Time to Hatch as Efficacious Indicators for Potential Nanotoxicity Assay in Zebrafish. Environmental Toxicology and Chemistry, 37, 3063-3076. https://doi.org/10.1002/etc.4266

[45] Bai, W., Tian, W., Zhang, Z., He, X., Ma, Y., Liu, N. and Chai, Z. (2010) Effects of Copper Nanoparticles on the Development of Zebrafish Embryos. Journal of $\mathrm{Na}$ noscience and Nanotechnology, 10, 8670-8676.

https://doi.org/10.1166/jnn.2010.2686

[46] Lee, W.S., Cho, H.J., Kim, E., Huh, Y.H., Kim, H.J., Kim, B., Kang, T., Lee, J.S. and Jeong, J. (2019) Bioaccumulation of Polystyrene Nanoplastics and Their Effect on the Toxicity of Au Ions in Zebrafish Embryos. Nanoscale, 11, 3173-3185.

https://doi.org/10.1039/C8NR09321K

[47] Pitt, J.A., Kozal, J.S., Jayasundara, N., Massarsky, A., Trevisan, R., Geitner, N., Wiesnerd, M., Levine, E.D. and Di Giulio, R.T. (2018) Uptake, Tissue Distribution, and Toxicity of Polystyrene Nanoparticles in Developing Zebrafish (Danio rerio). Aquatic Toxicology, 194, 185-194. https://doi.org/10.1016/j.aquatox.2017.11.017 